\title{
Decline curve analysis for multiple-fractured horizontal wells in tight oil reservoirs
}

\author{
Guohan $\mathrm{Xu}^{1,2}$, Hongjun Yin ${ }^{1,2} *$, Hongfei Yuan ${ }^{1,2}$, Cuiqiao Xing ${ }^{1,2}$ \\ ${ }^{1}$ Department of Petroleum Engineering, Northeast Petroleum University, Daqing 163000, P. R. China \\ ${ }^{2}$ Key Laboratory of Enhanced Oil Recovery (Northeast Petroleum University), Ministry of Education, Daqing 163000, P. R. China
}

\section{Keywords:}

Tight oil

rate-decline analysis

decline curve analysis model

sensitivity analysis

Cited as:

Xu, G., Yin., H., Yuan, H., Xing, C. Decline curve analysis for multiplefractured horizontal wells in tight oil reservoirs. Advances in Geo-Energy Research, 2020, 4(3): 296-304, doi: 10.46690/ager.2020.03.07.

\begin{abstract}
:
The production of multiple-fractured horizontal wells (MFHW) in tight oil reservoirs decreases rapidly in the initial period. It then enters a stable state of the low production with a slow loss-ratio. Because of its complicated production dynamic characteristics, the conventional rate-decline analysis method is no longer applicable. We adopt the semianalytical solution of the MFHW five-region linear flow model to get the multiple-fractured dimensionless rate-decline analysis curves and continuously calculate the loss-ratio of the decline curves. Based on the characteristics of the loss-ratio in the log-log plot, the decline curve analysis (DCA) model for tight oil MFHW is established. According to the DCA model, dimensionless production decline curves are obtained, and the sensitivity of the parameters in the model is analyzed. Finally, the DCA model is used to analyze the production rate decline of tight oil MFHW, and good matching results and production forecasts are achieved. This method provides a scientific basis for the rate-decline analysis of tight oil MFHW.
\end{abstract}

\section{Introduction}

Tight oil reservoirs have the characteristics of ultra-low permeability, and horizontal wells combined with multiplefracturing can increase the volume of stimulated reservoir and production of the wells, so it can effectively develop tight reservoirs (Ozkan et al., 2011; Hu et al., 2017). The production rates decline performance of the tight oil wells has a "twostage"characteristic. In the early stage, the tight oil wells have a high initial rate, and the loss-ratio is significant, while in the middle and late periods, the production rate is low, and the loss-ratio is slowly declining (Qanbari and Clarkson, 2014; Henrik et al., 2017). On account of the complex production dynamics of tight oil, the conventional method of rate-decline analysis is no longer applicable (Liang et al., 2013). The production dynamic characteristics analysis of tight oil wells and production prediction is one of the difficulties in the current reserve evaluation (Wang et al., 2014; Yu et al., 2019). Therefore, the establishment of a suitable rate-decline analysis method for tight oil wells is of great significance for the development of tight oil reservoirs.
Using precisely measured petrophysical information, combined with analytical, semi-analytical or numerical solutions can lead to reasonable production predictions based on accurate reservoir model analysis (Idorenyin and Shirif, 2018; Wang et al., 2019; Zhao and Du, 2020). However, building such a complex reservoir model for petrophysical experiments is expensive and time-consuming, as a variety of geological and petrophysical data needs to be collected and analyzed (Barzegar et al., 2012; Joshi and Lee, 2013; Ji et al., 2017). In contrast, decline curve analysis (DCA) only needs production data, and almost no reservoir information is required (Tan et al., 2018). The accuracy of DCA is sufficient to meet industrial needs, and it is very efficient. In essence, DCA models are regressions for historical production data (Kanfar and Wattenbarger, 2012; Paryani et al., 2018), and it can be used to predict the production rate and the cumulative production (Xi and Morgan, 2019).

DCA was first proposed by Arnold (1923), who assumed that the production rate at any time is a constant fraction of the rates at the preceding time. Johnson and Bollens (1927) proposed the concept of loss-ratio and derivative of loss-ratio

\section{Yandy} Scientific Press

${ }^{*}$ Corresponding author.

E-mail address: xgh1219973727@163.com (G. Xu); yinhj7176@126.com (H. Yin); yhf19951110@163.com (H. Yuan);

xincq888@163.com (C. Xing).

2207-9963 (c) The Author(s) 2020.

Received May 24, 2020; revised June 16, 2020; accepted June 22, 2020; available online July 1, 2020.
} 
through the study of dynamic production data, laying a foundation for the rate-decline analysis. The classical DCA model was proposed by Arps, where the author proposed a hyperbolic function with three parameters to simulate the decline of flow rate, but it is only suitable for pseudo-steady-state flows production period (Arps, 1945). However, the unstable production time of tight oil wells is long, and it is challenging to reach pseudo-steady-state flows. As a result, it may cause a large discrepancy between the production forecast and the actual. To generalize different Arps models in one expression so that there is no need to change formulas for different time intervals, Robertson (1988) proposed the following modified hyperbolic decline (MHD) model. Ilk et al. $(2008,2010)$ redefined the loss-ratio and came up with the power law exponential (PLE) Decline Model. It is based on the Arps decline curves and uses the power law to approximate the production rate, and it accounts for both transient and boundary-dominated flows. To avoid the disadvantages of the Arps decline model and use the relatively easier access of large dataset of well productions, Valk et al. $(2009,2010)$ proposed the stretched exponential production decline (SEPD) Model, but this model focuses on transient flow rather than the boundary-dominated flow, and requires a sufficiently long production time to accurately estimate the parameters. The Duong model is introduced based on one empirically derived rule, and it is more accurate for linear flows and bilinearlinear flows (Duong, 2011). Another piece of work to avoid using piecewise functions was done by Zhang et al. (2016), who combined the exponential form of the decline equation proposed by Fetkovich. This new method is called extended exponential decline curve analysis (EEDCA). This model can capture both the early production profile and the late production profile (Zhang et al., 2016). Wang et al. (2017) proposed a new empirical method and compared it with other DCA models such as the SEPD model and Duong model, and concluded that the SEPD underestimates estimated ultimate recovery (EUR) and the Duong model overestimates the ultimate recoveries. Han and Kwon (2018), according to the transient production performance of an MFHW in an unconventional gas field, present the selection of an appropriate (DCA) methodology by using the cumulative production incline rate. The rate introduced in this research is the change of cumulative production per unit time divided by the cumulative production. Furthermore, this method can be used to select a DCA method to forecast the production of unconventional gas wells. Jongkittinarukorn et al. (2019) present a new approach to improve production forecasts and reserve estimation for a multilayer well in the early stage of production using the hyperbolic decline method to model the decline rate of each layer. This method can provide decline parameters for each layer at an early stage of production that can then be used for production forecasting in the longterm. Qin et al. (2019) presents a mathematical model of an MFHW with considering segmented fracture for better evaluation of fracture and reservoir properties, by using DCA method, the influences of sensitive parameters on compound type curves are analyzed.

However, we still need to study a DCA model based on the semi-analytical solution of tight oil MFHW, which can model transient flows, pseudo-steady-state flows and boundary dominated flows, to predict the production rates of the tight oil wells.

This paper, through the dimensionless rate-decline curves of MFHW and based on the semi-analytical solution (Stalgorova and Mattar, 2013; Jiang et al., 2014), builds suitable DCA model for tight oil MFHW, takes into account the influence of the parameters in the model, draws the ratedecline dimensionless curves, and analyzes the sensitivity of the parameter, Finally, we apply the model to analyze field examples, further verifying the applicability of the model.

\section{Methodology}

\subsection{Production rate-decline curves of MFHW}

Commercial production from unconventional reservoirs requires extensive hydraulic fracturing of horizontal wells. It is postulated that such a stimulation practice creates a complex network of fractures, hence a region of higher permeability, around each hydraulic fracture, which is called stimulated reservoir volume (SRV), otherwise called unstimulated reservoir volume (USRV).

To model the MFHW, we assume that all fractures are spaced uniformly along with the horizontal wells and have the same length and conductivity. We introduce the SRV of higher permeability around each fracture to represent fracture branching, which are blue regions in Fig. 1, while the USRV are gray regions. This assumption is realistic because it is common field practice to design equally spaced hydraulic fractures with similar properties. Because of the symmetry of the model, we can perform calculations on one-quarter of the space between the fractures, as shown in Fig. 1(a). Space is divided into five regions and flows in the model, which is treated as a combination of five linear flows within contiguous areas, as shown in Fig. 1(b). It is the MFHW five-region linear flow model.

Dimensionless pressure is defined as:

$$
p_{D}=\frac{2 \pi n_{f} K_{1 f} h\left(p_{i}-p\right)}{q \mu B}
$$

Dimensionless distance from fracture to SRV boundary:

$$
x_{1 D}=\frac{x_{1}}{x_{f}}
$$

Dimensionless coordinate perpendicular to the horizontal well:

$$
y_{D}=\frac{y}{x_{f}}
$$

Dimensionless time:

$$
t_{D}=\frac{K_{1 f} t}{\left(\phi_{1 f} \mu C_{t 1 f}+\phi_{1 m} \mu C_{t 1 m}\right) x_{f}}
$$

Dimensionless fracture conductivity:

$$
F_{C D}=\frac{K_{F} w}{K_{1 f} x_{f}}
$$




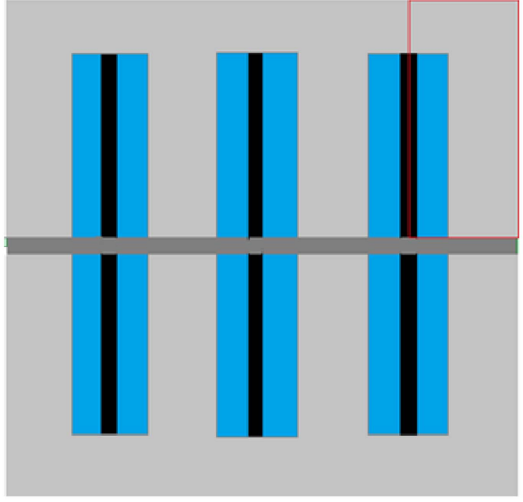

(a) Wells model

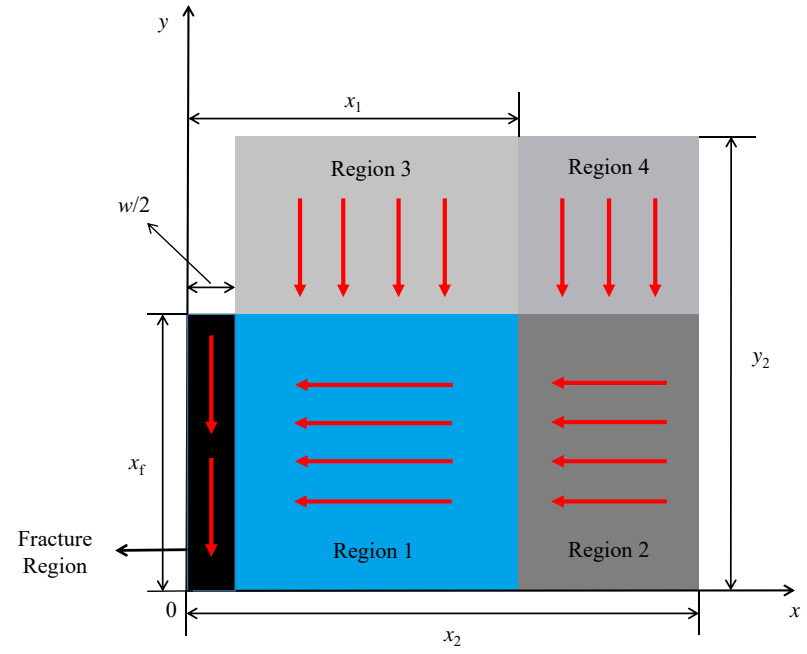

(b) Flow model

Fig. 1. MFHW five-region linear flow model (Stalgorova et al., 2013).

where $K_{F}$ and $K_{1 f}$ are the permeability of fracture and fracture system in the SRV $\left(\mathrm{m}^{2}\right) ; n_{f}$ is the number of fractures; $h$ is the net pay $(\mathrm{m}) ; p_{i}$ is initial reservoir pressure $(\mathrm{MPa}) ; \mu$ is viscosity (Pas); $B$ is liquid formation volume factor; $x_{1}$ is the distance from fracture to SRV boundary $(\mathrm{m}) ; x_{f}$ is the half fracture length (m); $t$ is time (day), and $\phi_{1 m}$ are porosity of the SRV fracture system and matrix system; $C_{t 1 f}$ and $C_{t 1 m}$ are total compressibility of the SRV fracture system and matrix system; and $w$ is fracture width (m).

By solving the five-region linear flow model, pressure solution in the Laplace space can be obtained:

$$
\bar{p}_{F D}=\frac{\pi \cos \left[\sqrt{a}\left(1-y_{D}\right)\right]}{s F_{C D} \sqrt{a} \sinh (\sqrt{a})}
$$

where $a$ is calculation parameters, if $y_{D}=0$, the pressure of fracture is the wellbore flowing pressure:

$$
\bar{p}_{w D}=\frac{\pi}{s F_{C D} \sqrt{a} \tanh (\sqrt{a})}
$$

Using stehfest numerical inversion and the relationship between pressure and production rates (Van Everdingen and Hurst, 1949), we can get the semi-analytical production solution of the MFHW.

$$
\bar{p}_{w D}(s) \bar{q}_{D}(s)=\frac{1}{s^{2}}
$$

where $s$ is Laplace operator.

By altering the dimensionless distance from fracture to SRV boundary $x_{1 D}$, the multiple-fractured dimensionless production rate-decline analysis of curves is obtained (Fig. 2).

As shown in the figure, the slope of the curves stays the same in earlier stages. Still, once the curves are affected by the boundary of stimulated reservoir volume, their slope will increase rapidly and then change to lines perpendicular to the horizontal coordinate axis.

The dimensionless production rate-decline curves of MFHW is representative and universal, which can reflect the

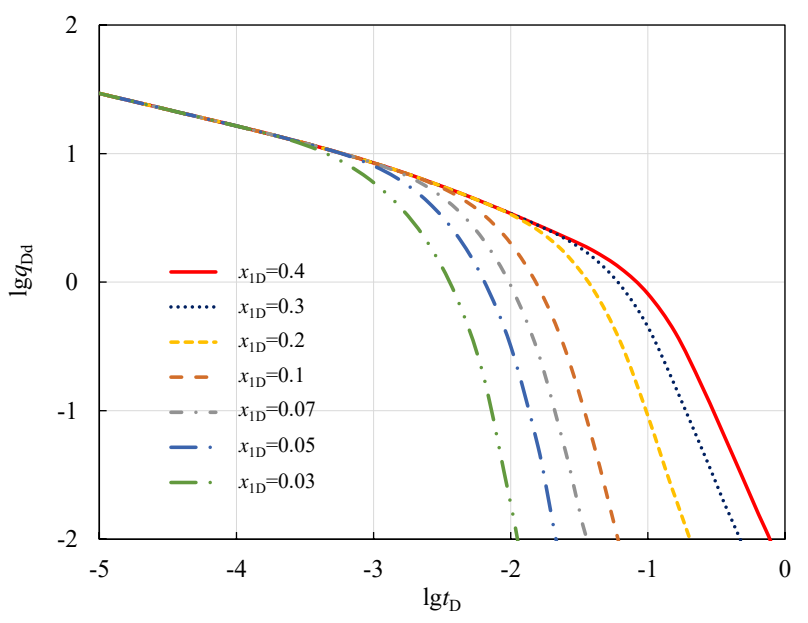

Fig. 2. Dimensionless rate-decline curves of MFHW.

law of rate-decline of MFHW. Therefore, the DCA model can be established based on the law presented in these curves.

\subsection{DCA model for MFHW}

Loss-ratio refers to the gradient of production rates per unit time, which uses to reflect the oil and gas well rates of decline, usually represented it by the letter $D$,

$$
D=-\frac{\Delta q}{q \Delta t}
$$

where $D$ is loss-ratio $\left(\right.$ day $\left.^{-1}\right), q$ is production rates of oil or gas wells $\left(\mathrm{m}^{3} /\right.$ day), $t$ is production time (day).

Analyzing the dimensionless rate-decline curves of MFHW, calculating the loss-ratio of different curves, we can get the log-log plot for $D$ and $t_{D}$ (Fig. 3).

Through the analysis of the curves in Fig. 3, we can state that the "power-law"behavior of the loss-ratio occurs in the 


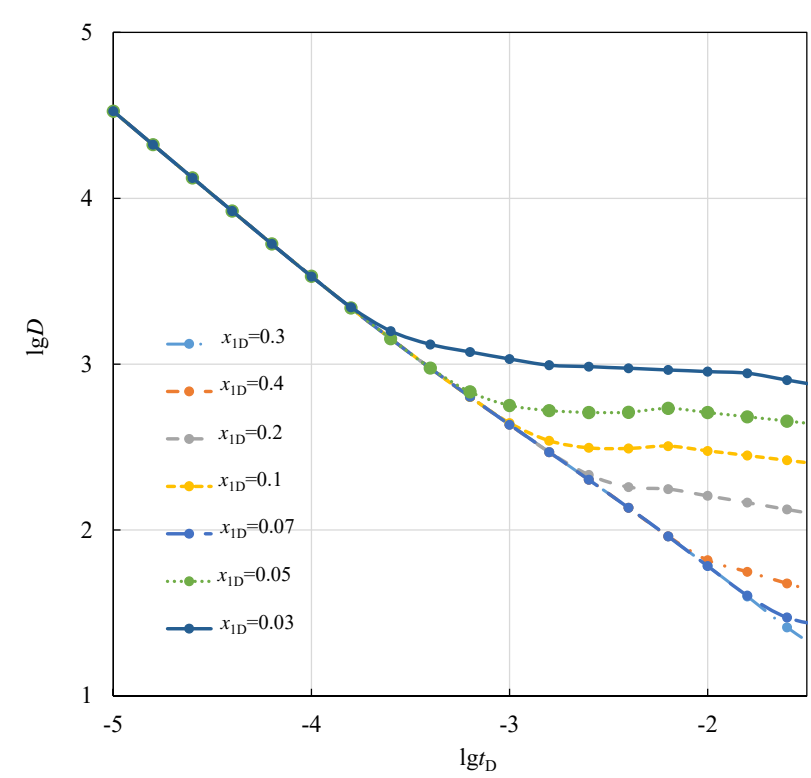

Fig. 3. $\log -\log$ curves for $D$ and $t_{D}$.

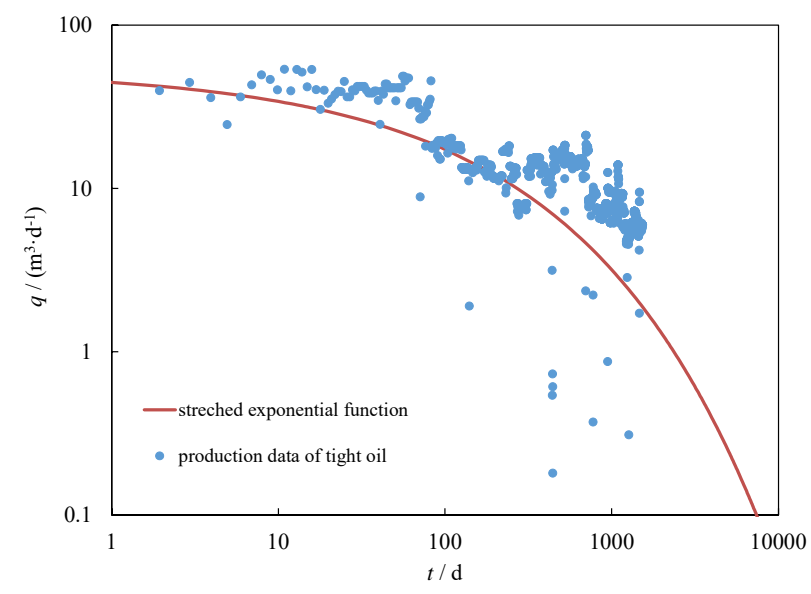

Fig. 4. Stretched exponential function matching effect.

early stage, which means loss-ratio is roughly a straight line on the log-log plot. However, the loss-ratio declining trend in later time becomes slow, and the curves are roughly horizontal lines on the log-log plot.

Based on the behavior of the curves observed in the log$\log$ plot, the $D$-parameter trend can be modeled by using a power-law equation which is given as:

$$
D(t)=D_{1} t^{-(1-n)}
$$

where $D_{1}$ is loss-ratio of the first day $\left(\right.$ day $\left.^{-1}\right) ; n$ is time exponent, and the value of the $n$ is usually between 0 and 1.

Substitute Eq. (10) into the loss-ratio definition Eq. (9) and solve the associated differential equation, and we can get an equation for the production rates:

$$
q(t)=\hat{q}_{i} \exp \left(-\hat{D}_{i} t^{n}\right)
$$

where $\hat{D}_{i}=D_{1} / n$.

Eq. (11) is called "stretched exponential function". Using this model to match the production data of any tight well (Fig. 4), it is found that the curve matching effect is useful in the early period, but as the production time increases, the tight oil well is in the state of low and stable production for a long time, the loss-ratio decreases, and the matching effect of the stretched exponential function is reduced.

To solve the weak matching effect of production data in the late period of tight oil well, it is necessary to modify the model of the stretched exponential function. So we introduce the new parameter $D_{\infty}$, which is infinite loss-ratio, and then according to the relationship of loss-ratio with time, redefine the loss-ratio, which is given as:

$$
D=D_{\infty}+D_{1} t^{-(1-n)}
$$

where $D_{\infty}$ is infinite loss-ratio $\left(\right.$ day $\left.^{-1}\right)$; the value of the $D_{\infty}$ is usually between $10^{-5}$ and $10^{-3}$.

The physical meaning of Eq. (12) is that when the production time is relatively short, the power-law term is the main influencing factor of the redefined loss-ratio, which can be approximated by the power-law term. However, as the production time gradually increases and approaches infinity, the power-law term has less influence on the loss-ratio model, and the loss-ratio tends to infinity loss-ratio $D_{\infty}$.

Substitute Eq. (12) into Eq. (9) and integrate the separated variables to obtain the expression of the DCA model, which applies to MFHW:

$$
q=\hat{q}_{i} \cdot \exp \left(-D_{\infty} t-\hat{D}_{i} t^{n}\right)
$$

Eq. (13) indicates that in the early period of production, the production rate characteristics are controlled by $\hat{D}_{i}$ term. In the late period of production, which reaches pseudo-steadystate flows or boundary dominated flows, the rate is mainly controlled by $D_{\infty}$.

Tight oil wells have long transient production cycles, so it is difficult to reach the boundary pseudo-steady-state flows period, and tight oil wells have been in a state of low and steady production for a long time. The conventional ratedecline analysis method is only suitable for the pseudo-steadystate flows period of tight oil wells. In contrast, the DCA model established by this method can match the production data before the pseudo-steady-state flows period, and we get a good matching effect (Fig. 5). The parameters are listed in Table 1. Therefore, this model is suitable for MFHW.

\section{Result}

\subsection{Characteristic curves of DCA model}

Based on the DCA model for tight oil MFHW, and using parameters from Table 2, we can get the characteristic curves of this model (Fig. 5).

As shown in Fig. 6, the loss-ratio was a line with slope $(n-1)$ in the early times of the log-log plot, while it approaches a horizontal line in the later times. It is because the initial ti- 


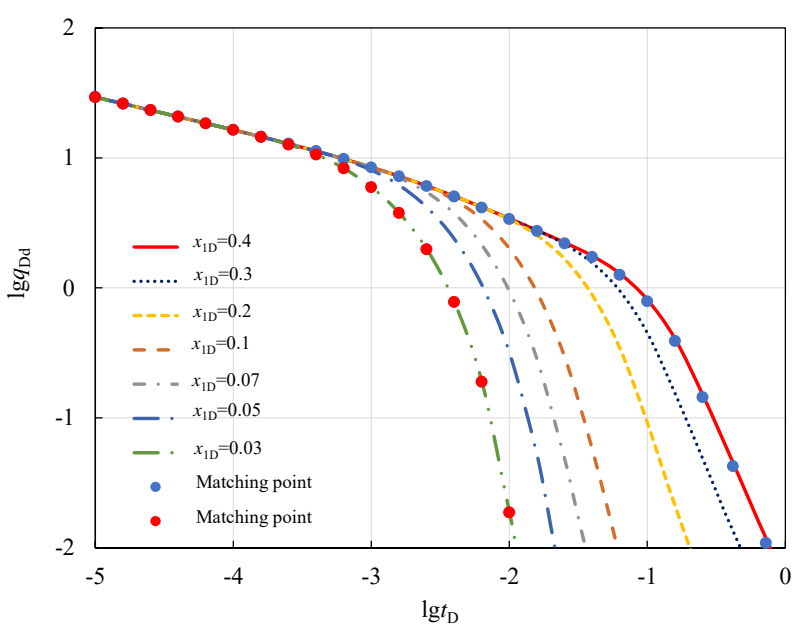

Fig. 5. Matching effect of the DCA model.

Table 1. Matching parameters of the DCA model.

\begin{tabular}{ll}
\hline \multicolumn{2}{c}{ Matching point 1} \\
\hline Parameters & Value \\
\hline Initial rate $q_{i}\left(\mathrm{~m}^{3} \mathrm{day}^{-1}\right)$ & 29.38 \\
Infinite loss-ratio $D_{\infty}\left(\mathrm{day}^{-1}\right)$ & 0.0001 \\
Initial loss-ratio $D_{i}\left(\mathrm{day}^{-1}\right)$ & 0.05 \\
Time exponent & 0.5 \\
\hline \multicolumn{1}{c}{ Matching point 2 } \\
\hline Parameters & Value \\
\hline Initial rate $q_{i}\left(\mathrm{~m}^{3} \mathrm{day}^{-1}\right)$ & 29.37 \\
Infinite loss-ratio $D_{\infty}\left(\mathrm{day}^{-1}\right)$ & 0.0001 \\
Initial loss-ratio $D_{i}\left(\mathrm{day}^{-1}\right)$ & 0.06 \\
Time exponent & 0.5 \\
\hline
\end{tabular}

Table 2. Parameters for the DCA model.

\begin{tabular}{ll}
\hline Parameters & Value \\
\hline Initial rate $q_{i}\left(\mathrm{~m}^{3} \mathrm{day}^{-1}\right)$ & 20.0 \\
Infinite loss-ratio $D_{\infty}\left(\mathrm{day}^{-1}\right)$ & 0.005 \\
Initial loss-ratio $D_{i}\left(\mathrm{day}^{-1}\right)$ & 0.1 \\
Time exponent & 0.5 \\
\hline
\end{tabular}

me is so short that $D_{\infty}$ has a negligible effect on loss-ratio; as the time increases, the impact of time-dependent term gradually decreases, and $D_{\infty}$ becomes the main influencing factor. The curve of rates in the log-log plot early period shows a hyperbolic decreasing form, while the curve shows the exponential decreasing way at a later time.

\subsection{Dimensionless production rate-decline curves of DCA model}

Dimensionless production rates is defined as:

$$
q_{D d}=\frac{q}{\hat{q}_{i}}
$$

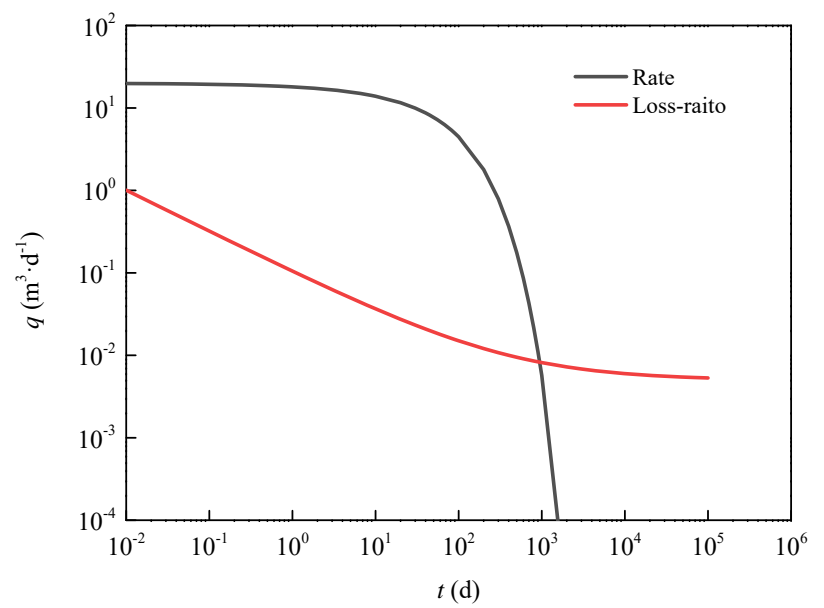

Fig. 6. Characteristic curves of the DCA model.

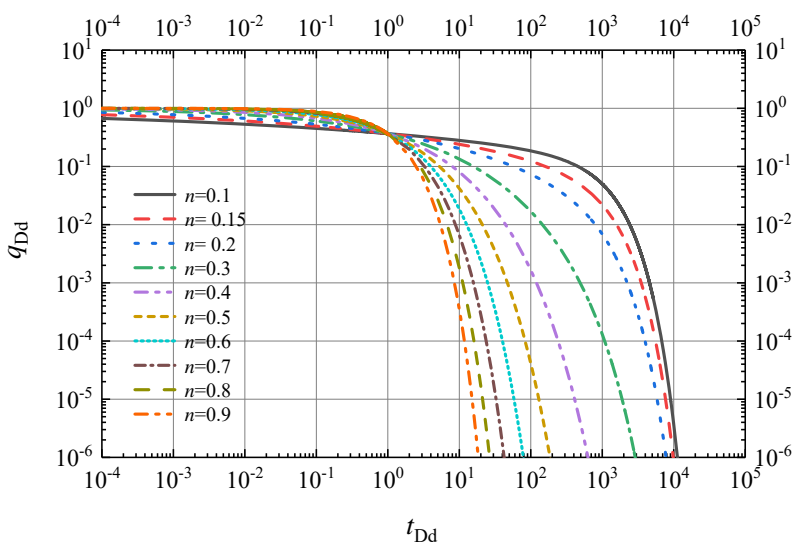

Fig. 7. Dimensionless rate-decline curves with different time exponent.

Dimensionless time:

$$
t_{D d}=\hat{D}_{i}^{\frac{1}{n}} t
$$

Dimensionless infinite loss-ratio:

$$
\tilde{D}_{\infty}=\frac{D_{\infty}}{\hat{D}_{i}^{\frac{1}{n}}}
$$

Substitute the above dimensionless definition into Eq. (13) the dimensionless rate-decline model is obtained:

$$
q_{D d}=\exp \left(-\tilde{D}_{\infty} t_{D d}-t_{D d}^{n}\right)
$$

Use Eq. (17) to draw dimensionless rate-decline curves with different time exponent (Fig. 7).

As shown in Fig. 7, tight oil production rates decline rapidly in the early period, and the decline curves approximate to a horizontal line at the beginning of the log-log plot. As time lengthens, the rate is basically stable with a slow decline, and decline curves gradually become a straight line perpendicular to the horizontal axis in the log-log plot. The larger the time exponent $n$, the faster the rates decline, and the shorter the tight wells development time. 


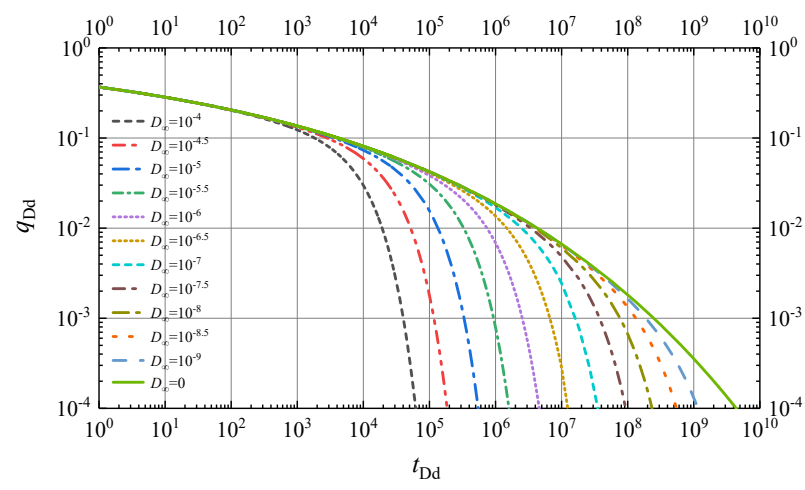

Fig. 8. Dimensionless rate-decline curves with different infinite loss-ratio.

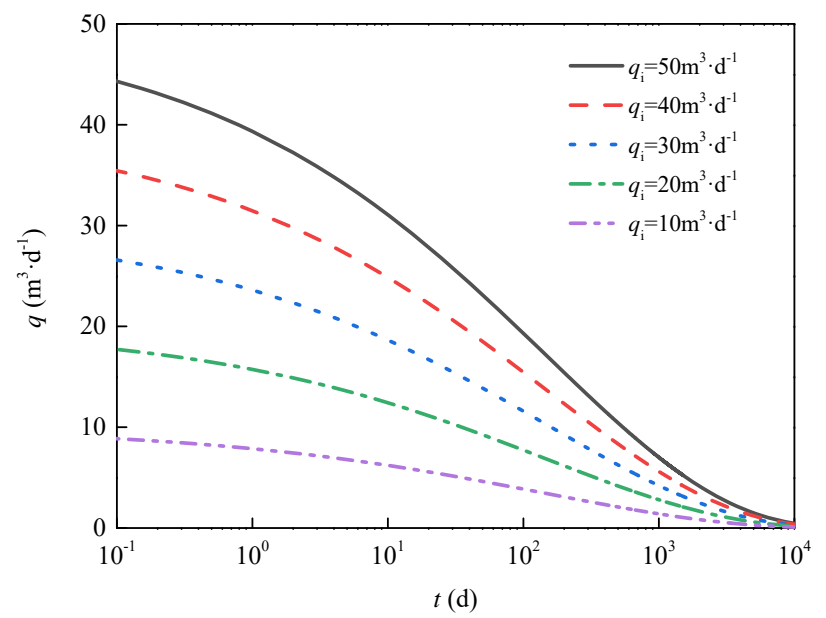

Fig. 9. The effect of initial rate on production rates.

As shown in Fig. 8, dimensionless infinite loss-ratio controls how fast the curves approach the horizontal axis in the $\log -\log$ plot. The larger the parameter, the earlier it approaches the horizontal axis in the log-log plot, and the shorter the development time of tight oil wells.

\subsection{Parameter sensitivity analysis of the model}

Sensitivity analysis is performed on the initial rate, infinite loss-ratio, initial loss-ratio and decline index. The influence of each parameter on the shape of the production rate curves is explained using the method of control variables. Different coordinates are used to draw the curves. In addition to rectangular coordinates, there are semi-log and $\log$-log coordinates, which fully illustrate the impact of various parameters on the characteristics of the decline curves.

The influence of the initial rate on the decline curves in semi-log coordinates is shown in Fig. 9. The initial rate controls the entire curve to move up and down, but the curves corresponding to different initial rates only fluctuate significantly in the early period, while as time lengthens, the curve in the later period does not change much.

The influence of the infinite loss-ratio on the decline curves in $\log$-log coordinates is shown in Fig. 10. Infinite loss-ratio

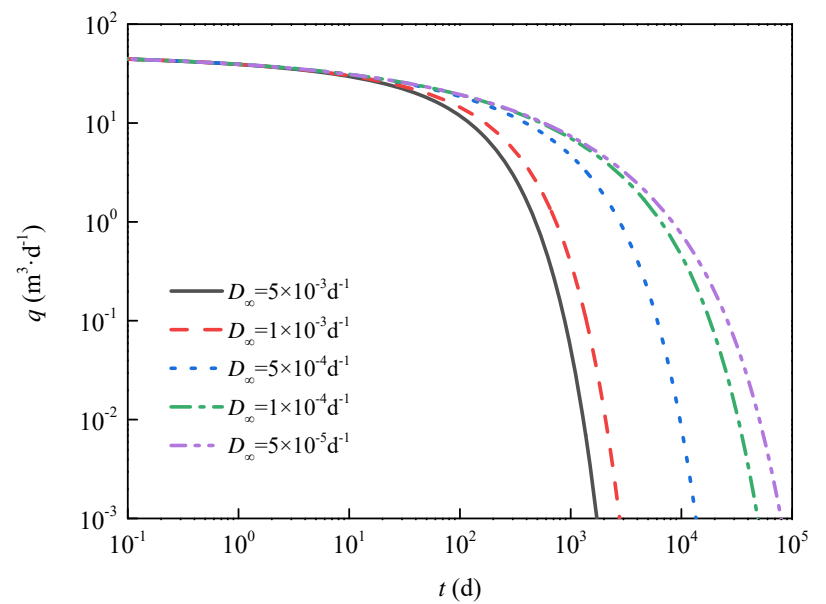

Fig. 10. The effect of infinite loss-ratio on production rates.

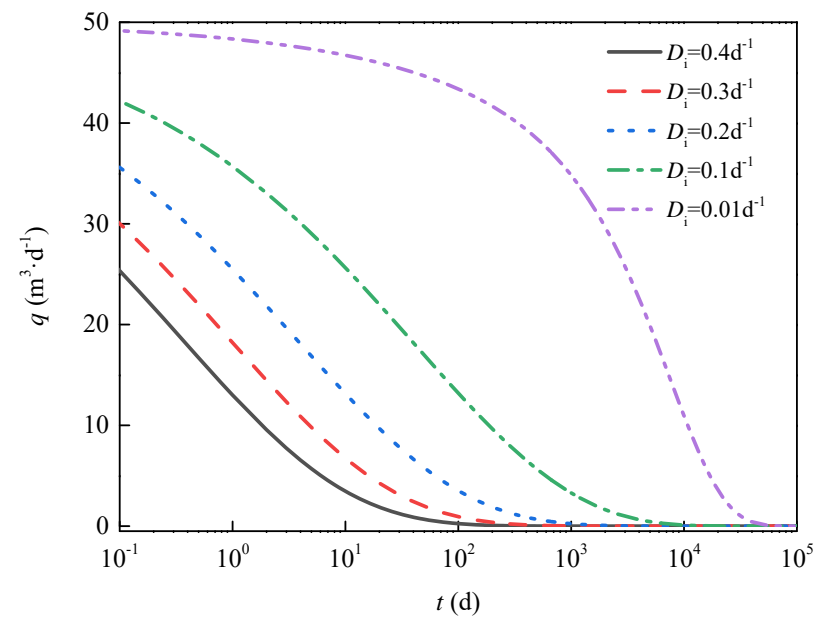

Fig. 11. The effect of initial loss-ratio on production rates.

controls how fast the curve approaches the horizontal axis over time on the log-log plot; the larger the infinite loss-ratio, the earlier the trend of the curve approaches the horizontal axis appears.

The influence of the initial loss-ratio on the decline curves in semi-log coordinates is shown in Fig. 11. Initial loss-ratio control decline speed of curves in the early period, the larger the parameter, the greater the decline degree of the curves is. In addition, initial loss-ratio also controls how fast the curve approaches the horizontal axis at the later period; the larger the initial loss-ratio is, the faster the curve approaches the horizontal axis at the later period.

The influence of the time exponent on the decline curves in rectangular coordinates is shown in Fig. 12. The time exponent controls the convexity of the curves in the early period, and the larger the time exponent, the more concave the curve is, and the greater the decline degree of the curve is.

\section{Discussion}

Well YP is an MFHW in Fuyu tight oil reservoir from 


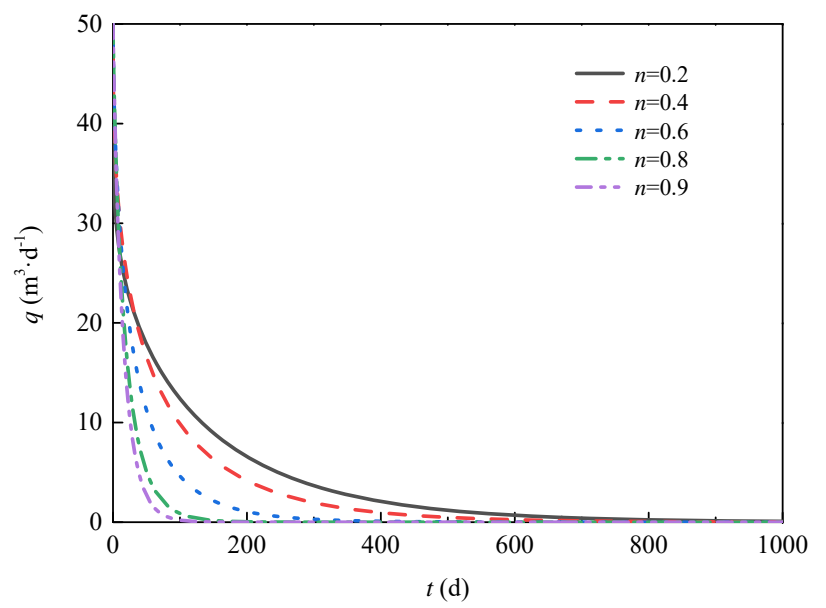

Fig. 12. The effect of time exponent on production rates.

Table 3. Parameters for model matching.

\begin{tabular}{ll}
\hline Parameters & Values \\
\hline Initial rate $q_{i}\left(\mathrm{~m}^{3} \mathrm{day}^{-1}\right)$ & 22.13 \\
Infinite loss-ratio $D_{\infty}\left(\mathrm{day}^{-1}\right)$ & 0.00065 \\
Initial loss-ratio $D_{i}\left(\mathrm{day}^{-1}\right)$ & 0.07 \\
Time exponent $n$ & 0.25 \\
Goodness of match discrimination coefficient $R^{2}$ & 0.65 \\
\hline
\end{tabular}

Changyuan, Daqing. The original formation pressure of the well is $16.9 \mathrm{MPa}$; the reservoir thickness is $2.0 \mathrm{~m}$; the tight oil reservoir porosity is 0.126 ; the fluid density is 0.9215 $\mathrm{g} / \mathrm{cm}^{3}$, and the tight oil reservoir permeability is $0.17 \mathrm{mD}$. The well began production in April 2014, and has taken fifty-four months so far. We use the DCA model to match the production data (Fig. 12). The parameters used are shown in Table 3.

The loss-ratio equation is:

$$
D=0.0001+0.0712 t^{-0.715}
$$

The rates decline equation is:

$$
q=53.28 \exp \left(-0.0001 t-0.2498 t^{0.297}\right)
$$

As shown in Fig. 13, the theoretical rates curve is basically consistent with the measured rates trend, and the predicted cumulative production curve is basically in agreement with the actual cumulative production curve. That is to say, the DCA model for MFHW can well match the production data of well YP.

The DCA model can be used to predict the production rates and cumulative production of the well. When the rate declines to $3 \mathrm{~m}^{3} / \mathrm{d}$, it takes 9.3 years, and the cumulative production is $25,102.4 \mathrm{~m}^{3}$; when the rate declines to $1 \mathrm{~m}^{3} / \mathrm{d}$, it takes 21.2 years, and the cumulative production is $32,712.3$ $\mathrm{m}^{3}$. When tight oil wells have been in production for 50 years, the rate declines to $0.143 \mathrm{~m}^{3} / \mathrm{d}$, and the cumulative production is $37,154.1 \mathrm{~m}^{3}$; when tight oil wells have been in production for 100 years, the rate declines to $9.4410^{-3} \mathrm{~m}^{3} / \mathrm{d}$, and the cumulative production is $38,022.1 \mathrm{~m}^{3}$.

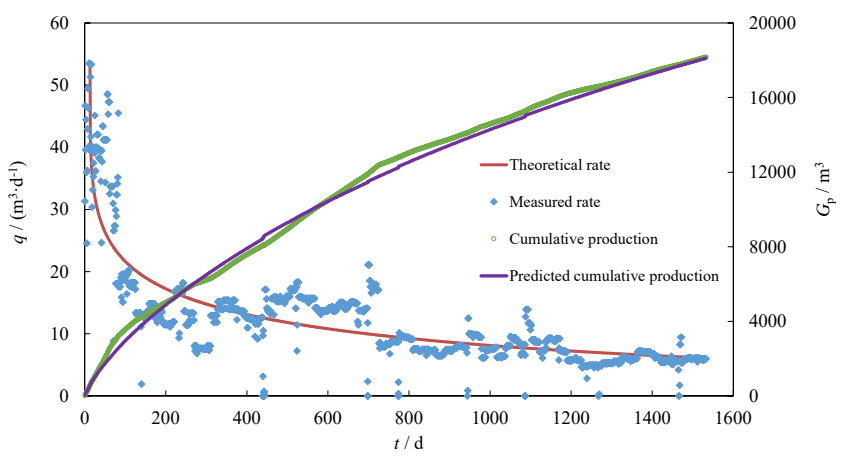

Fig. 13. The DCA model matching curve of well YP.

\section{Conclusion}

We use a semi-analytical solution of the MFHW five-region linear flow model to simulate the decline curves, which alter the dimensionless distance from fracture to SRV boundary $x_{1 D}$. Based on the law of the loss-ratio of the curve in the log-log plot, the modified stretched exponential function is used, and the DCA model for tight oil MFHW is obtained.

The DCA model established in this paper can be used to analyze steady flows, transient flows and boundary dominated flows. It can more accurately predict the production and cumulative production of tight wells. So this DCA model is suitable for the rate-decline analysis of tight oil MFHW.

Production rates of tight oil wells decline rapidly in the early period, while as production time increases, production rates of wells tend to stabilize and remain low for a long time. The typical production decline curve is approximately a straight line parallel to the horizontal axis of the log-log plot in the early period; as time lengthens, the curve gradually passes into a line perpendicular to the horizontal axis. The earlier this trend appears, the higher the time exponent and the shorter the development time of tight oil wells.

By using the DCA model to analyze the rates decline of well YP, the production data and cumulative production data of the tight well are well matched; loss-ratio equation and rate decline equation are obtained. This DCA model provides an effective method for the production decline analysis of tight oil MFHW.

\section{Acknowledgement}

The authors would like to acknowledge the National Science and Technology Major Project of 2017ZX05071 for providing research data and funding.

\section{Conflict of interest}

The authors declare no competing interest.

Open Access This article, published at Yandy Scientific Press on behalf of the Division of Porous Flow, Hubei Province Society of Rock Mechanics and Engineering, is distributed under the terms and conditions of the Creative Commons Attribution (CC BY-NC-ND) license, which permits unrestricted use, distribution, and reproduction in any medium, provided the original work is properly cited. 


\section{References}

Arnold, R. Two decades of petroleum geology, 1903-22. AAPG Bull. 1923, 7(6): 603-624.

Arps, J.J. Analysis of decline curve. Trans. AIME 1945, 160(1): 228-247.

Barzegar Alamdari, B., Kiani, M., Kazemi, H. Experimental and numerical simulation of surfactant-assisted oil recovery in tight fractured carbonate reservoir cores. Paper SPE 153902 Presented at SPE Improved Oil Recovery Symposium, Tulsa, Oklahoma, USA, 14-18 April, 2012.

Duong, A.N. Rate-decline analysis for fracture-dominated shale reservoirs. SPE Reserv. Eval. Eng. 2011, 14(3): 377-387.

Han, D., Kwon, S. Selection of decline curve analysis method using the cumulative production incline rate for transient production data obtained from a multi-stage hydraulic fractured horizontal well in unconventional gas fields. Int. J. Oil Gas Coal Technol. 2018, 18(3-4): 384-401.

Henrik, W., Linnea, L., Kjell, A., et al. Production decline curves of tight oil wells in eagle ford shale. Nat. Resour. Res. 2017, 26(3): 365-377.

Hu, J., Zhang, C., Rui, Z., et al. Fractured horizontal well productivity prediction in tight oil reservoirs. J. Pet. Sci. Eng. 2017, 151: 159-168.

Hu, Y., Weijermar, R., Zuo, L., et al. Benchmarking EUR estimates for hydraulically fractured wells with and without fracture hits using various DCA methods. J. Pet. Sci. Eng. 2017, 162: 617-632.

Idorenyin, E.H., Shirif, E. Semi-analytical solution for modeling the performance of complex multifractured horizontal wells in unconventional reservoirs. SPE Reserv. Eval. Eng. 2018, 21(4): 961-980.

Ilk, D., Currie, S., Symmons, D., et al. Hybrid rate-decline models for the analysis of production performance in unconventional reservoirs. Paper SPE 135616 Presented at SPE Annual Technical Conference and Exhibition, Florence, Italy, 19-22 September, 2010.

Ilk, D., Rushing, J.A., Perego, A.D., et al. Exponential vs. hyperbolic decline in tight gas sands: Understanding the origin and implications for reserve estimates using Arps decline curves. Paper SPE 116731 Presented at SPE Annual Technical Conference and Exhibition, Denver, CO, USA, 21-24 September, 2008.

Ji, J., Yao, Y., Huang, S., et al. Analytical model for production performance analysis of multi-fractured horizontal well in tight oil reservoirs. J. Pet. Sci. Eng. 2017, 158: 380397.

Jiang, R., Xu, J., Sun, Z., et al. Rate transient analysis for multistage fractured horizontal well in tight oil reservoirs considering stimulated reservoir. Math. Probl. Eng. 2014, 2014: 489015.

Johnson, R.H., Bollens, A.L. The loss ratio method of extrapolating oil well decline curves. Trans. AIME 1927, 77(1): 771-778.

Jongkittinarukorn, K., Last, N., Escobar, F.H., et al. A new decline curve analysis method for layered reservoirs.
Paper SPE 195085 Presented at SPE Middle East Oil and Gas Show and Conference, Manama, Bahrain, 18-21 March, 2019.

Joshi, K., Lee, W.J. Comparison of various deterministic forecasting techniques in shale gas reservoirs. Paper SPE 163870 Presented at SPE Hydraulic Fracturing Technology Conference, Woodlands, Texas, USA, 4-6 February, 2013.

Kanfar, M., Wattenbarger, R. Comparison of empirical decline curve methods for shale wells. Paper SPE 162648 Presented at SPE Canadian Unconventional Resources Conference, Calgary, Alberta, Canada, 30 October-1 November, 2012.

Zhao, K., Du, P. A new production prediction model for multistage fractured horizontal well in tight oil reservoirs. Adv. Geo-Energy Res. 2020, 4(2): 152-161.

Liang, T., Chang, Y., Guo, X., et al. Influence factors of single well's productivity in the Bakken tight oil reservoir, Williston basin. Pet. Explor. Dev. 2013, 40(3): 383-388.

Male, F. Assessing impact of uncertainties in decline curve analysis through hindcasting. J. Pet. Sci. Eng. 2019, 172: 340-348.

Ozkan, E., Brown, M.L., Raghavan, R., et al. Comparison of fractured-horizontal-well performance in tight sand and shale reservoirs. SPE Reserv. Eval. Eng. 2011, 14(2): 248-259.

Paryani, M., Ahmadi, M., Awoleke, O., et al. Decline curve analysis: A comparative study of proposed models using improved residual functions. J. Pet. Environ. Biotechnol. 2018, 9(1): 1-8.

Qanbari, F., Clarkson, C.R. Production data analysis of multi-fractured horizontal wells producing from tight oil reservoirs-bounded stimulated reservoir volume. Paper SPE 167727 Presented at SPE/EAGE European Unconventional Conference and Exhibition, Vienna, Austria, 25-27 February, 2014.

Qin, J., Cheng, S., He, Y., et al. Decline curve analysis of fractured horizontal wells through segmented fracture model. J. Energy Resour. Technol. 2019, 141(1): 012903.

Robertson, S. Generalized hyperbolic equation. Paper SPE 18731 Presented at Society of Petroleum Engineers, Richardson, TX, USA, 1 January, 1988.

Stalgorova, K., Mattar, L. Analytical model for unconventional multifractured composite system. SPE Reserv. Eval. Eng. 2013, 16(3): 246-256.

Tan, L., Zuo, L., Wang, B. Methods of decline curve analysis for shale gas reservoirs. Energies 2018, 11(3): 552.

Valk, P.P. Assigning value to stimulation in the Barnett shale: A simultaneous analysis of 7000 plus production histories and well completion records. Paper SPE 119369 Presented at SPE Hydraulic Fracturing Technology Conference, Woodlands, TX, USA, 19-21 January, 2009.

Valk, P.P., Lee, J.W. A better way to forecast production from unconventional gas wells. Paper SPE 134231 Presented at SPE Annual Technical Conference and Exhibition, Florence, Italy, 19-22 September, 2010.

Van Everdingen, A.F., Hurst, W. The application of the laplace transformation to flow problems in reservoirs. J. Pet. 
Technol. 1949, 1(12): 305-324.

Wang, H., Liao, X., Lu, N., et al. A study on development effect of horizontal well with SRV in unconventional tight oil reservoir. J. Energy Inst. 2014, 87(2): 114-120.

Wang, K., Li, H., Wang, J., et al. Predicting production and estimated ultimate recoveries for shale gas wells: A new methodology approach. Appl. Energy 2017, 206: 14161431.

Wang, W., Fan, D., Sheng, G., et al. A review of analytical and semi-analytical fluid flow models for ultra-tight hydrocarbon reservoirs. Fuel 2019, 256: 115737.
Xi, Z., Morgan, E. Combining decline-curve analysis and geostatistics to forecast gas production in the Marcellus shale. SPE Reserv. Eval. Eng. 2019, 22(4): 1562-1574.

Yu, Y., Chen, Z., Xu, J. A simulation-based method to determine the coefcient of hyperbolic decline curve for tight oil production. Adv. Geo-Energy Res. 2019, 3(4): 375-380.

Zhang, H., Rietz, D., Cagle, A., et al. Extended exponential decline curve analysis. J. Nat. Gas Sci. Eng. 2016, 36: 402-413. 